\title{
Real predicates and existential judgements
}

\author{
Ralf M. Bader \\ Merton College, University of Oxford
}

\section{Real predicates}

One of the central commitments of Kant's (pre-Critical as well as Critical) modal theory is the claim that existence is not a determination/real predicate. Judging that something exists does not amount to determining the concept in question, but instead involves the absolute positing of the thing together with all its predicates. This claim plays a crucial role in Kant's critique of the ontological argument, and also constitutes the core of his general theory of modal representation. This paper criticises the interpretation of real predicates put forward by Stang in his important book Kant's Modal Metaphysics (Stang: 2016).

Kant states that "die Bestimmung ist ein Prädicat, welches über den Begriff des Subjects hinzukommt und ihn vergrößert” (A598/B626). This suggests that a concept is being determined when the predicate is not contained within the concept of the thing of which it is predicated. Determining a concept, accordingly, involves predicating a predicate that is synthetic relative to that concept. Whether a predicate $\mathrm{P}$ determines a concept $\mathrm{C}$ is a relative matter, insofar as $\mathrm{P}$ can determine $\mathrm{C}$ yet fail to determine $\mathrm{C}^{\prime}$. By contrast, whether a predicate $\mathrm{P}$ is a real predicate is an absolute matter that does not involve any relativisation, i.e. every predicate $\mathrm{P}$ is either a real predicate or it is a merely logical predicate. The absolute notion can be understood in terms of the relative notion, insofar as a real predicate is one that can be used in synthetic predication, i.e. a predicate that is synthetic relative to some concept C. In this way, we end up with the synthetic predicate interpretation, which holds that real predicates are ones that can be used for determining concepts, where this amounts to synthetic predication.

\section{I.I An inconsistent triad}

According to Shaffer, the synthetic predicate interpretation is inconsistent with Kant's theory of existential judgements.

\footnotetext{
${ }^{*}$ Thanks to Ian Proops for helpful discussions.
} 
What is a 'real' predicate? Kant defines it as something 'which is added to the concept of the subject and enlarges it'. This is a most unfortunate definition for Kant to use, however, since it leads to a contradiction with another important doctrine of his, that existential propositions are always synthetic. Synthetic judgments are those which 'add to the concept of the subject a predicate which has not been in any wise thought in it', and if existential judgments are always synthetic then 'exists' must be a predicate which adds to the concept of the subject, in short, a 'real' predicate as defined above. (Shaffer: 1962, p. 309)

A judgement is synthetic if the predicate is synthetic with respect to the subject of the judgement. From this it would seem to follow that existence judgements can only be synthetic on the grounds that what is predicated in such a judgment, namely existence, is a synthetic predicate. Yet this is precisely what Kant appears to be denying when claiming that existence is not a real and hence not synthetic predicate.

I. Existence is not a real predicate.

2. Existence judgements are synthetic.

3. Judgements are synthetic in virtue of the predicate being synthetic relative to the subject of the judgement.

Given the synthetic predicate interpretation, we end up with an inconsistent triad since this interpretation licenses one to infer from existence not being a real predicate to it not being a synthetic predicate (relative to any concept), which is incompatible with the other two claims.

There are two options as to how this inconsistency can be resolved. Either one claims that existence is a synthetic predicate. This would allow one to explain straightforwardly why existence judgements are synthetic. Yet, it requires one to reject the interpretation of what it is to be a real predicate in terms of being a synthetic predicate. Or one denies that existence is a synthetic predicate, in which case one has to provide an alternative account of what makes existence judgements synthetic. In particular, the challenge will be to provide a unified account of what a judgement is and what it is for a judgement to be synthetic that yields the result that existence judgements classify as being synthetic. ${ }^{\mathrm{I}}$

\section{Synthetic non-real predicates}

Stang adopts the former strategy for avoiding the inconsistent triad. This requires a disalignment of the distinction between real and merely logical predicates from that between predicates that are synthetic with respect to some subject and those

${ }^{\text {I} C f . ~ " K a n t ' s ~ t h e o r y ~ o f ~ m o d a l i t y " ~(B a d e r: ~ m a n u s c r i p t) ~ f o r ~ s u c h ~ a n ~ a l t e r n a t i v e ~ a c c o u n t . ~}$ 
that are not synthetic with respect to any subject. In particular, though one can accept that all real predicates are synthetic, one has to deny the converse claim that every synthetic predicate is a real predicate. This allows one to claim that existence is a synthetic yet non-real predicate, such that existence does not determine any concept even though it adds to the concept of the subject in an existence judgement.

In order to defend this strategy one has to provide an alternative account of determination. Following van Cleve, Stang has developed an interpretation of what it is to determine a concept / to be a determination that makes room for synthetic non-real predicates (Stang: 2016, p. 39):

DEFN A concept $\mathrm{P}$ determines a concept $\mathrm{C}$ if and only if it is possible that there is an object that instantiates $\mathrm{C}$ and $\mathrm{P}$ and it is possible that there is an object that instantiates $\mathrm{C}$ but not $\mathrm{P}$.

DEFN A predicate $\mathrm{P}$ is a determination if and only if $\mathrm{P}$ determines at least one concept.

On this account, existence is not a real predicate because " $<$ existence $>$ and $<$ nonexistence $>$ do not possibly divide the extension of any concept. The extension of no concept divides into existing and non-existing instances of that concept because there are no non-existent objects" (Stang: 2016, p. 42). ${ }^{2}$ That is, existence fails to be a real predicate because there are no merely possible objects and hence it is not possible for there to be a concept the extension of which is divided by <existence $>$ and $<$ non-existence $>$.

By making room for synthetic non-real predicates, this interpretation supposedly "allows us to escape the inconsistent triad of views; just because <exists> does not determine any subject concept, it does not follow that existence is not a synthetic predicate" (Stang: 20I6, p. 40). This account thus departs from the synthetic predicate interpretation both in terms of how to understand what it is for $\mathrm{P}$ to determine $\mathrm{C}$ and in terms of how existence is understood. In particular, it has the following distinctive commitments:

I. Synthetic predicates that necessarily apply to a concept $\mathrm{C}$ do not determine that concept.

2. Existence is a synthetic predicate, even though it is not a determination/real predicate.

${ }^{2}$ Cf. "there is no concept $\mathrm{C}$ such that $\diamond \exists \mathrm{x}(\mathrm{Cx} \& \neg \mathrm{Ex})$. This, at any rate, is a consequence of letting the existential quantifier express existence. To suppose there is something $(\exists \mathrm{x} . .$.$) that$ does not exist $(\ldots \neg \mathrm{Ex})$ is to suppose there is something that there is not" (van Cleve: I999, p. I 88). 


\section{I Determination as extension-dividing predication}

The claim that a predicate determines a concept by dividing or restricting its extension is inadequate. Kant frequently uses the notion of determination when concerned with synthetic predicates that are necessarily had by objects falling under the concept in question. Accordingly, a predicate $\mathrm{P}$ can be a determination of $\mathrm{C}$, even though what falls under $\mathrm{C}$ might necessarily fall under P. Necessary synthetic determinations enlarge a concept even though they do not divide the extension of the concept.

I. Kant claims that $\langle$ body $>$ is determined by $<$ being heavy $>$, yet that $<b o d y>$ is not determined by <being extended $>$, since the latter is already contained in the concept $<$ body $>$ (cf. 29:8I9). The former is synthetic, whereas the latter is analytic. Yet, <being heavy $>$ necessarily applies to every body. The predicate < being heavy $>$ is an accidens predicamentale not a contingent predicabile (cf. 28:638 and 29:1004).

(Stang tries to deal with recalcitrant texts by suggesting that they are to be interpreted as using Baumgarten's notion of a determination, rather than the technical Kantian sense (cf. Stang: 20 I 5, p. 599 fn 32). Yet, this strategy is not applicable to the case at hand, since Kant uses this example precisely to illustrate the difference of his account from that of Baumgarten.)

2. In the 2nd Critique, Kant argues that we have to postulate the existence of God in order for the highest good to be possible and that it allows us to attribute various features to God, such as omnipotence, omnipresence and being eternal. In this way, "the moral law, by means of the concept of the highest good as the object of a pure practical reason, determines the concept of the original being as the supreme being, something that the physical (and, pursued higher, the metaphysical) and so the whole speculative course of reason could not effect" (5:I40). The concept of God can accordingly be determined in various ways, yet God could not have failed to have any of those features.

3. Mathematical concepts can be determined even though the relevant predicates apply necessarily. ${ }^{3}$ At $\mathrm{A}_{732} / \mathrm{B} 760$ Kant claims that $<$ being curved $>$ is a determination of <circle $>$ (or, more precisely, <circular line $>$ (Kreislinie)), yet is not to be included in its definition. Stang discusses this passage, suggesting that: "However, I think it is clear that Kant is here claiming that curved is a determination (it determines the concept line) but it is not a determination of circle; that is why it is incorrect to include it in the definition of circle" (Stang: 201 5, p. 599 fn 32). Yet, this is not what is going on. Kant is saying that $<$ being curved $>$ is a determination but not

${ }^{3}$ Cf. 4:288, 4:374-375, R4674, R4678, R5083. 
one that is to be included in the definition because it is superfluous, since it can be "deduced from the definition" (A732/B760). The common explication which includes <being curved $>$ does not classify as a definition because it is lacking in "Präcision" (A73 I/B759). Including this determination violates the second of the three conditions of a definition: "Ausführlichkeit bedeutet die Klarheit und Zulänglichkeit der Merkmale; Grenzen die Präcision, daß deren nicht mehr sind, als zum ausführlichen Begriffe gehören; ursprünglich aber, daß diese Grenzbestimmung nicht irgend woher abgeleitet sei und also noch eines Beweises bedürfe" (A727/B755).

In addition to these textual difficulties, the interpretation is also problematic on substantive grounds. This is because the explanation that existence is not a determination, on the basis that it fails to divide the extension of any concept, cannot be generalised to the other modal categories. According to Kant, not only existence but all modal categories fail to be real predicates. "Die Kategorien der Modalität haben das Besondere an sich: daß sie den Begriff, dem sie als Prädicate beigefügt werden, als Bestimmung des Objects nicht im mindesten vermehren, sondern nur das Verhältniß zum Erkenntnißvermögen ausdrücken" (A2 I9/B266).

Stang can straightforwardly deal with (logical) possibility since "it is not possible for there to be (absolute positing) an object that does not instantiate the concept <possible>" (Stang: 2016, p. I65). However, the account breaks down when concerned with restricted notions of possibility. Although Stang is correct in claiming that "it is (formally) impossible that there is a phenomenon that is not formally possible" (Stang: 2016, p. 219), such that "<formally possible> does not determine <phenomenon>" (Stang: 20I6, p. 219 fn 7I), this does not suffice for establishing that $<$ formally possible $>$ is not a determination. Since to be a determination it suffices for there to be some concept that is determined by it, simply showing that <phenomenon $>$ is not determined by $<$ formally possible $>$ is not enough to establish that the latter is not a determination. Even though it does not determine <phenomenon $>$, it may very well determine a higher concept such as <logically possible object $>$. In particular, something can be logically possible without being possible in a restricted sense, such that it is logically possible for there to be an object, such as a noumenon, that does not instantiate the concept <formally possible $>$, which would imply, given Stang's interpretation, that $<$ formally possible $>$ is a determination. ${ }^{4}$

${ }^{4}$ At p. 2 I9 Stang makes a qualified claim: the modal predicates $<$ formally possible $>$ and $<$ empirically necessary> "are not determinations of the domain of objects for which they are defined". Since the modal predicates are not meant to be determinations of any domain of objects, Stang would have to argue that these predicates are inapplicable to things other than phenomena. However, instead of claiming that these predicates are only defined for phenomena, one should hold that there is one domain that is partitioned by the categories of possibility and impossibility. There is one domain of objects, the members of which are classified as formally possible v. for- 
Further difficulties arise when dealing with necessity. Stang argues that his interpretation of empirical-causal necessity does satisfy this requirement, insofar as "it is (formally) impossible that there is an alteration that is not empirically necessary" (Stang: 2016, p. 219). Yet, it is logically possible that there is an alteration that is not empirically necessary. ${ }^{5}$ More troubling still, Stang does nothing to render the unrestricted notion of necessity compatible with Kant's claim that modal predicates are not real predicates. The problem, in particular, is that God is an entity that we have to posit (on both theoretical and practical grounds) and one that we have to consider as being necessary (in fact as being absolutely necessary), yet other things, e.g. immoral actions, are meant to be contingent. This means that the existing things (in general) are divided into those that are necessary and those that are contingent, even though 'necessity' and 'contingency' are not real predicates. This does not cohere with Stang's interpretation. ${ }^{6}$

mally impossible depending on whether they are compatible or incompatible with the forms of experience. If being formally possible were only applicable for phenomena, whilst being formally impossible were only defined for other things, such as noumena, then saying that a noumenon, such as God, is formally possible would not be a substantive mistake, but would rather be something along the lines of a category mistake. Moreover, if $\mathrm{P}$ is defined for $\mathrm{C}$, then it should also be defined for any higher concept $\mathrm{C}^{\prime}$. Hence, even though $\mathrm{P}$ does not divide the extension of $\mathrm{C}$, it may very well divide the extension of $\mathrm{C}^{\prime}$.

${ }^{5}$ Unfortunately, Stang does not tell us which notion of possibility we are supposed to use when assessing whether 'it is possible that there is an object that instantiates $\mathrm{C}$ and $\mathrm{P}$ and it is possible that there is an object that instantiates $C$ but not P'. If logical possibility is at issue, then his claims on p. 39 about 'necessary' synthetic predicates not being determinations are false. After all, it is logically possible that there is an object that falls under the concept <triangle> but not under the concept <having interior angles that sum to I80 degrees $>$. If real possibility is at issue, then we will only have a limited supply of determinations. Since the real possibility of God cannot be established (by theoretical reason), we cannot establish the real possibility of an object instantiating the divine attributes, yet they are meant to be determinations, in fact perfections, that form the basis of the omnitudo realitatis, which constitutes the transcendental substratum of the thoroughgoing determination of all things (A 575/B603). The "storehouse of material from which all possible predicates of things can be taken" will then be rather empty, and reason might not be able to fulfil its regulative role and consider all realities to be nothing but limitations of the omnitudo realitatis.

${ }^{6} \mathrm{~A}$ further problem is that certain predicates are necessarily instantiated by everything that exists, yet it is far from clear that all of them should be classified as non-real predicates: e.g. <being self-identical $>$, <being such as to perfectly resemble oneself $>$, and, most problematically, certain disjunctive properties like <being identical to God or grounded in God $>$. By disjoining all (atomic) real predicates one ends up with a predicate that cannot divide the extension of any concept, which means that Stang is committed to the set of real predicates not being closed under (infinitary) disjunction. This is problematic since it implies that, according to Stang's account, there are lots of non-real predicates other than the modal categories. As a result, being a non-real predicate is not something that is distinctive of modal predicates. The problem then is to account for the crucial difference between the modal predicates and other non-real predicates. 


\subsection{Existence as a synthetic predicate}

Stang's approach makes room for synthetic non-real predicates. This ensures that the fact that existence is not a real predicate does not preclude it from being a synthetic predicate. Accordingly, one can no longer infer from existence not being a real predicate to it not being a synthetic predicate. As a result, we no longer end up with an inconsistent triad. ${ }^{7}$

However, it is far from clear whether Kant allows for synthetic non-real predicates. Stang cites the Metaphysik Mrongovius: "the logical predicate can be analytic, but determination is always synthetic" (29:8I9), stating that: "He notably does not claim that all and only synthetic predicates are determinations" (Stang: 20I6, p. 40, fn II3). At best this shows that Kant does not explicitly rule out Stang's interpretation in this passage, but does not positively support it. Moreover, Kant illustrates this claim precisely by means of the contrast between 'body is extended' and 'body is heavy', which, as we have seen, is inconsistent with Stang's interpretation. Furthermore, only a few lines later Kant explicitly states that a determination is a synthetic predicate: "Bestimmung ist ein synthetisches praedicat" (29:819).

More generally, the claim that there are synthetic non-real predicates is subject to textual problems. There is plenty of textual evidence to the effect that 'determination' and 'synthetic predicate' are to be identified.

I. In $\mathrm{R}_{4674}$ determinations are contrasted with analytic predicates.

2. "determinatio est praedicatum syntheticum" (R570I).

3. "Alle Bestimmung ist synthesis" (R5703)

4. "Alles synthetische Prädicat, d.i. determination" (R64I3).

5. "Praedicata analytica nennen wir nicht Determinationen, sondern die praedicata synthetica" (28:552).

6. "Bey den Categorien haben wir unter dem 4ten Titel, nehmlich unter der Modalitaet, angeführt : Moglichkeit, Wirklichkeit und Nothwendigkeit, dann haben wir befunden, daß sie gar nicht Bestimmungen eines Dings sind oder synthetische Praedicate; sie sind nehmlich Begriffe, wodurch ein Ding mit allen Praedicaten gesetzt wird" (29:82 I).

Not only is there lots of textual support to the effect that determinations are to be identified with synthetic predicates, which allows one to infer from existence not being a determination to it not being a synthetic predicate, there are also passages in which Kant explicitly rejects the claim that existence is a synthetic predicate.

\footnotetext{
${ }^{7}$ Completely resolving the inconsistency would require one not only to make room for synthetic non-real predicates, but to positively establish that existence is in fact a synthetic predicate.
} 
For instance in the passage from 29:82 I quoted above, Kant makes clear that existence is not a synthetic predicate. Also R57 I2: "Possibile etc. etc. sind keine synthetische praedicate."

Since this is enough to generate Shaffer's inconsistency, there is a direct way of arriving at the supposed inconsistency that does not proceed via an account of determination but starts with the claim that existence is not a synthetic predicate. Generating the inconsistency does not require one to appeal to the synthetic predicate interpretation of what it is to be a real predicate. Accordingly, we can see that interpretations of determination that do not identify it with synthetic predication do not succeed in addressing this problem. An alternative resolution is thus required.

\section{References}

[I] Kant, I. Kants gesammelte Schriften. Reimer/de Gruyter, I900.

[2] Shaffer, J. Existence, predication and the ontological argument. Mind 7I, 283 (I962), 307-325.

[3] Stang, N. Kant's argument that existence is not a determination. Philosophy and Phenomenological Research 9I, 3 (2015), 583-626.

[4] Stang, N. Kant's Modal Metaphysics. Oxford University Press, 20 i6.

[5] van Cleve, J. Problems from Kant. Oxford University Press, I 999. 